\title{
A Combined Program of Cadaveric and Living-Related Liver Transplantation in a Single Center: An Experience of 1,000 Operations
}

\author{
Florin Botea ${ }^{1}$, Bogdan Dorobantu ${ }^{1}$, Sorin Alexandrescu ${ }^{1}$, Mihai Grigorie ${ }^{1}$, Emil Matei ${ }^{1}$, Radu Zamfir ${ }^{1}$, \\ Vasile Lungu' ${ }^{1}$, Dragos Zamfirescu' ${ }^{2}$, Dana Tomescu ${ }^{3}$, Gabriela Droc ${ }^{3}$, Daniela Ungureanu ${ }^{3}$, Ruxandra Fota ${ }^{3}$, \\ Gratiela Manga ${ }^{3}$, Mihai Popescu ${ }^{3}$, Liana Gheorghe ${ }^{4}$, Speranta lacob ${ }^{4}$, Corina Pietrareanu ${ }^{4}$, \\ Mariana Mihaila ${ }^{4}$, Laurentiu Micu ${ }^{4}$, Cristian Gheorghe $^{4}$, Bogdan Cotruta ${ }^{4}$, Sanda Constantinescu ${ }^{5}$, \\ Ioana Lupescu', Mugur Grasu', Mirela Boros ${ }^{6}$, Radu Dumitru', Mihai Toma ${ }^{6}$, Liliana Paslaru', Laura Vlad7, \\ Ileana Constantinescu ${ }^{7}$, Ileana Dima ${ }^{7}$, Vlad Herlea ${ }^{8}$, Gabriel Becheanu ${ }^{8}$, Catalin Pecheanu ${ }^{8}$, \\ Daniela Sasalovici ${ }^{1}$, Doina Hrehoret ${ }^{1}$, Vladislav Brasoveanu ${ }^{1}$, Mihnea lonescu ${ }^{1}$, Irinel Popescu ${ }^{1 *}$
}

\author{
*Corresponding author: \\ Irinel Popescu, MD, FACS, FEBS \\ Professor of Surgery \\ "Dan Setlacec" Center of General \\ Surgery and Liver Transplantation \\ "Fundeni" Clinical Institute \\ Sos. Fundeni, 258, 022328 \\ Bucharest, Romania \\ Tel/Fax: 40-213180417 \\ E-mail: irinel.popescu@icfundeni.ro
}

\author{
1"Dan Setlacec" Center of General Surgery and Liver Transplantation, Fundeni Clinical Institute, Bucharest, \\ Romania \\ 2Zetta Center of Excellence in Plastic Surgery and Reconstructive Microsurgery, Bucharest, Romania \\ ${ }^{3}$ Department of Anesthesiology and Intensive Care, Fundeni Clinical Institute, Bucharest, Romania \\ ${ }^{4}$ Department of Gastroenterology and Hepatology, Fundeni Clinical Institute, Bucharest, Romania \\ ${ }^{5}$ Department of Pediatrics, Fundeni Clinical Institute, Bucharest, Romania \\ ${ }^{6}$ Department of Imaging and Interventional Radiology, Fundeni Clinical Institute, Bucharest, Romania \\ ${ }^{7}$ Department of Laboratory Medicine, Fundeni Clinical Institute, Bucharest, Romania \\ ${ }^{8}$ Department of Pathology, Fundeni Clinical Institute, Bucharest, Romania
}

\author{
Abbreviations: \\ LT: liver transplantation; \\ DDLT: deceased donor liver \\ transplantation; \\ LDLT: living donor liver transplantation; \\ HBV: hepatitis B virus; \\ HCV: hepatitis C virus; \\ HCC: hepatocellular carcinoma; \\ ECD: extended criteria donors; \\ MELD: model of end-stage liver disease; \\ PELD: pediatric end-stage liver disease; \\ WL: waiting list.
}

Received: 10.12.2020

Accepted: 12.02.2021

Copyright (C) Celsius Publishing House www.sgo-iasgo.com

\section{ABSTRACT}

Background: The liver transplantation program of Fundeni Clinical Institute reached a milestone (1000 operations performed by the same team in 20 years). It is a program for both adults and children, including cadaveric and living donor liver transplantations. We analyze the indications and results to emphasize the advantages of a combined program.

Methods: Between April 2000 and March 2020, 957 patients received 1,000 LTs at a single institution (Fundeni Clinical Institute, Bucharest, Romania). The demographics of donors and recipients, indications for liver transplantations, surgical procedures and results were analyzed.

Results: Deceased donor liver transplantation (DDLT): 831 DDLTs in 790 patients (83.1\%): whole LT in 769 patients (80.4\%), split LT in 17 patients (2\%), reduced-size LT in 2 patients $(0.5 \%)$, auxiliary $\mathrm{LT}$ in 1 patient $(0.1 \%)$ and domino $\mathrm{LT}$ in 1 patient $(0.1 \%)$. Living donor liver transplantation (LDLT): 169 LDLTs in 167 patients (17.2\%) using right hemiliver in 121 patients $(12.6 \%)$, left lateral section in 28 patients $(2.9 \%)$, left hemiliver in 9 patients $(0.9 \%)$, left hemiliver with segment 1 in 6 patients $(0.6 \%)$, and dual graft LDLT in 3 patients $(0.3 \%)$. Overall major morbidity rate was $42.2 \%$ (422 patients), while perioperative mortality was 8.3\% (79 patients). Retransplantation rate was 4.5\% (43 patients). The estimated 1-, 3-, 5and 10 -year overall survival rates for LT patients were $82.3 \%, 77.8 \%, 76.3 \%$ and $71.2 \%$, respectively.

Conclusions: A combined cadaveric and living donor LT program including all surgical variant $L T$ procedures offers the possibility to increase the volume with the well-known consequences on the postoperative results. The living donor program has a positive influence on the waiting list mortality; using both cadaveric and living donors enhance the possibilities in the case of an urgent retransplantation. 
Key words: liver transplantation, deceased donor liver transplantation, extended criteria donors, living donor liver transplantation, split liver transplantation, domino liver transplantation, dual graft living donor liver transplantation, liver machine perfusion, ABO-incompatible LT

\section{INTRODUCTION}

Since the first human deceased donor liver transplantations (DDLT) performed by T.E. Starzl in 1963 (1), followed by R. Calne (2), R. Pichlmayer, and H. Bismuth (3), and the first living donor liver transplantations (LDLT) performed by S. Raia, R.W. Strong, C. Broelsch in pediatric patients (4-6), and M. Makuuchi (7), K. Tanaka (8), S. T. Fan (3) in adult starting with 1989 , significant improvements occurred regarding: indications, donorrecipient matching and optimal timing, prolongation of the ischemic tolerance, surgical techniques, new immunosuppressive regimens, etc. LT has become an established therapy with over 20.000 procedures yearly worldwide (9). Survival rates after LT have significantly improved due to refinement in surgical techniques, anesthetic management, aggressive nursing care and prompt detection and treatment of complications. The request for LT continues to increase while the donor pool size remains inadequate.

\section{Development of liver transplantation in Romania}

In Romania, after several experimental LTs carried out during the second half of the 20th century, the LT program was started in Fundeni Clinical Institute by Irinel Popescu (Chief of Surgical Department) and the late Dan Tulbure (Chief of Intensive Care Department), in cooperation with Domenico Forti and Abdallah Slim (Italy) for the cadaveric program, and with Christoph Broelsch and Massimo Malago (Germany) for the living program. The first (unsuccessful) cadaveric LT was performed in 1997, followed by the first successful whole graft LT in 2000, while the first pediatric living donor liver transplantation (LDLT) in a child (successful) later the same year (10), and the first adult LDLT (successful) in 2003. By the end of 2006, the transplant center reached 20 LTs per year, the minimum number recommended for satisfactory results (11-14). Later on, in 2011, the center became a high-volume center exceeding 50 LTs per year (11-14), with the highest number of 122 LTs in 2013.

\section{MATERIAL AND METHODS}

\section{Waiting list}

Our policy for the management of the waiting list (WL) was described elsewhere (15).

\section{Recipients}

Between April 2000 and March 2020, 957 pts who received 1000 LTs (including retransplantation) in a single institution (Fundeni Clinical Institute, Bucharest, Romania) were retrospectively analyzed. All recipients were regularly followed-up by a multi-disciplinary team. Main medical records were retrospectively analyzed.

All candidates for LT were evaluated using standardized criteria based on general status, clinical symptoms, laboratory tests, imagery, MELD/PELD score, and liver tumor features replaced recently by the LIRADS score. Our protocol for managing the recipients prior to LT was previously described (15).

Complications classified as at least III A DindoClavien grade were considered as major complications (16). Perioperative mortality accounted for the intraoperative and 30-day postoperative deaths.

To compare the results, the recipients were allocated to the 3 periods of transplantation center development: low-volume center, defined as up to 20 recipients yearly (Group 1), mid-volume center (Group 2), defined as 20 to 50 recipients yearly, and high-volume center defined as over 50 recipients yearly (11-14). Hence, Group 1 encompassed 96 recipients transplanted from April 2000 to December 2006, Group 2 - 148 recipients transplanted from January 2007 to December 2010, and Group 3 - 713 recipients transplanted from January 2011 to March 2020.

\section{Indications for liver transplantation}

LT was offered to both adult and pediatric patients based on standardized indications (15).

\section{Surgical technique}

The surgical techniques for graft harvesting and implantation were standard and described elsewhere (17-19). 
Of note, in whole graft LT, for venous reconstruction we used the triangular cavo-cavostomy as standard technique (15), that replaced the techniques described by the Starzl and Belghiti (initially used, till 2003) (20). For bile duct reconstruction, we used choledococholedocal anastomosis without T-tube biliary drainage as standard technique; the use of the T-tube was abandoned after our initial experience. For LDLT, we favored the use of the right hemiliver leaving the middle hepatic vein in the donor, thus reconstructing the venous drainage in case of segmental veins of at least 5 $\mathrm{mm}$ in diameter; the artery was anastomosed using microsurgery when the diameter was under $5 \mathrm{~mm}$.

\section{Immunosuppression}

The used immunosuppressive regimens were according to the international recommendations and were previously described $(15,20)$.

\section{Donors}

Both deceased and living donors were used. In Romania, the non-heart beating donation was not introduced yet.

\section{Deceased donors}

The protocol for the deceased donors was described elsewhere $(15,20)$.

\section{Extended criteria liver graft donors}

Our policy for the extended criteria donors (ECD) was according to international recommendations (21), and was previously described (15).

Other sources for liver grafts were considered, such as methanol-poisoning, liver trauma, benign liver tumors and Takayasu syndrome (22).

\section{Hypothermic oxygenated mechanical perfusion of liver grafts}

The lack of donor organs and ischemia-reperfusion injury after static cold preservation of liver graft have led to the clinical implementation of machine oxygenation and perfusion technique of grafts, aiming to improve graft function and to reduce posttransplant complications, especially in case of ECD grafts. The HOPE (hypothermic oxygenated mechanical perfusion) procedure proved to have such benefits, therefore we introduced in the year 2016.

According with perfusion temperature, the procedure may be normothermic $\left(36-37^{\circ} \mathrm{C}\right)$ (23), subnormothermic $\left(20-28^{\circ} \mathrm{C}\right)$ (24) and hypothermic oxygenated perfusion $\left(12-14^{\circ} \mathrm{C}\right)(25)$. Moreover, the procedure may involve dual perfusion (both portal vein and hepatic artery) or single perfusion (portal vein only) (26). In our experience, we used the hypothermic oxygenated mechanical perfusion, with both single and dual approaches, using the LiverAssist $^{\circledR}$ device (OrganAssist, Holland) and Belzer UW ${ }^{\circledR}$ machine perfusion solution. We performed dual HOPE in grafts with liver steatosis or grafts with multiple extended criteria, as we felt more confident to use both portal and artery approaches for improving the graft function. For the other grafts, we preferred the single HOPE for its simplicity and avoidance of potential artery injuries due to cannulation and mechanical perfusion.

\section{Living donors}

Our protocol for assessing the living donors prior to transplantation was according to the generally accepted guidelines and described elsewhere $(15,18,27)$.

\section{Donor-recipient matching}

The main criteria for donor-recipient matching that we used were body mass index, graft weight and $A B O$ blood type compatibility. We usually allocated grafts with multiple criteria for ECD to recipients with liver cirrhosis with low MELD score with HCC beyond Milan criteria. When decompensated possible, we avoided to use ECD grafts for transplantation in recipients with severe comorbidities, high MELD score and/or with $\mathrm{HCV}$ infection. Additionally, we usually avoided liver grafts from cadaveric donors with age above 50 years for transplantation in recipients with HCV-related cirrhosis, in order to avoid early post-transplant HCV recurrence (28). For recipients with HCC within Milan Criteria with stable disease, we applied the same policy as for the non-HCC recipients, while for recipients with HCC within Milan Criteria but with aggressive disease progression while on waiting list, or those beyond Milan Criteria, we usually used ECD grafts or grafts from living donors (27). For urgent $L T$ and retransplantation, we developed protocols for ABO-incompatible LT (29).

\section{Statistical analysis}

The analyzed parameters were: waiting list related parameters (indication for LT, MELD/PELD score), patient demographics (age, blood type, body mass index), graft type, intraoperative features (operative time, blood loss, warm and cold ischemia time), short and long-term outcome. Categorical information was evaluated using the Chi-squared test. Continuous data were characterized by the median and range and 
evaluated using Student's t-test. Overall survival and comparative survival in the 3 groups - Group 1 (20002006), Group 2 (2007-2010), and Group 3 (2011-2020) - were investigated based on overall mortality (perioperative and postoperative mortality). To compare the long-term survival in terms of $\mathrm{LT}$ indications, only the postoperative mortality (deaths after at least 1 month after transplantation) was considered, in order to eliminate from the analysis the mortality unrelated to the scrutinized LT indications. The survival was statistically analyzed using the Kaplan-Meier method and the Log rank test. A $p$ value of $<0.05$ was considered statistically significant.

\section{RESULTS}

\section{Waiting list}

In our center, the waiting list for LT was constantly increasing since 2000, with 162 patients by the end of 2005 , and 427 patients at the beginning of 2011. Since 2011, the inclusion rate on the WL remained rather stable. By the end of 2019, there were 468 patients on the WL. Overall, 2415 patients were included on the WL since 2000.

The 1- and 3-year mortality rate on the WL for 20002010, 2011-2016, and 2017-2020 were 25.3\%, 13\% and $18.6 \%$ ( $p<0.0001)$, and $46.5 \%, 23.5 \%$ and $29 \%$, respectively $(p<0.0001)$. This was probably due to the increase of the donor number after 2011.

In what time to LT in relation to blood groups is concerned, before 2011, the median time to LT for patients with blood type group $O, A, B$, and $A B$ were 67.1, 99.8, 39.8, and 59.5 months, respectively. After 2011, the time to LT for the blood type groups decreased to $20,40.3,32.5$ and 28.4 months, respectively $(p<0.001)$.

\section{Recipients}

In the overall group of 957 recipients, the male/ female ratio was $566 / 391$, the adult/pediatric ratio was $887 / 70$, and the mean age was 46 yrs (median 50, range 7 months -68 yr) (fig. 1).

\section{Indications}

In our experience, HBV cirrhosis (262 pts; $26.2 \%$ ), HCC (212 pts; 21.2\%), and HCV cirrhosis (142 pts; 14.2\%) were the main indications for LT (fig. 2). The indications in adult and pediatric recipients are depicted in figs. 3 and 4, respectively. The evolution of the indications over time are illustrated in fig. 5; of

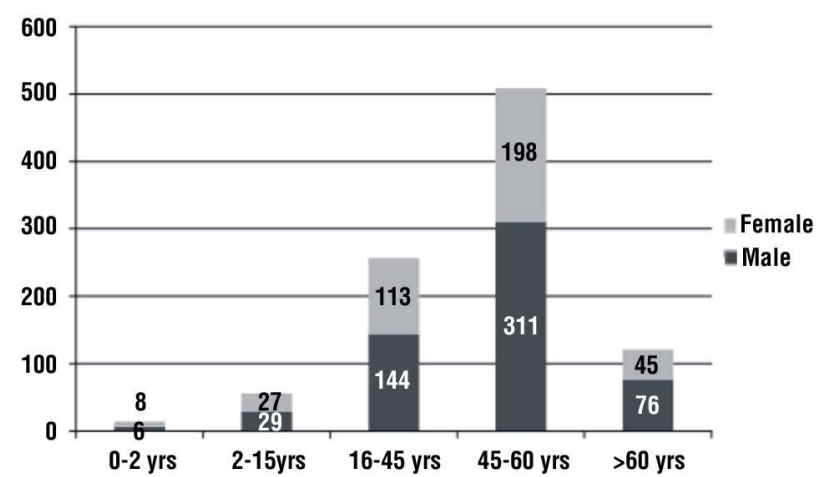

Figure 1 - Gender and age distribution of LT recipients

note, the incidence of VHB-related cirrhosis decreased while the VHC-related cirrhosis increased. In recipients with HBV-related cirrhosis, HDV coinfection was recorded in 188 out of 262 pts (71.7\%). HBV infection was associated with HCV-related cirrhosis in 13 out of the 142 pts (9.1\%). Out of the 212 recipients transplanted for HCC, 138 recipients were within Milan Criteria (65\%).

\section{Liver transplantation}

We performed 831 DDLTs in 790 patients (83.1\%), and 169 LDLTs in 167 patients (16.9\%) (table 1 and fig. 6); 41 patients required retransplantation using DDLT and 2 patients required retransplantation using LDLT. For the 790 DDLT recipients, we used whole graft (769 pts; $80.4 \%)$, split graft LT (17 pts; $1.7 \%$ ), reduced-size graft LT (2 pts; $0.2 \%$ ), domino LT (1 pt; $0.1 \%$ ), and auxiliary LT (1 pt; $0.1 \%$ ) For split graft LT, we used 5 left lateral sections, 2 left hemilivers, 3 right hemilivers, and 7 extended right hemilivers. The split graft LT procedures in adult and pediatric programs are showed in table 1 and table 2. For the domino LT, we used a whole liver retrieved from a

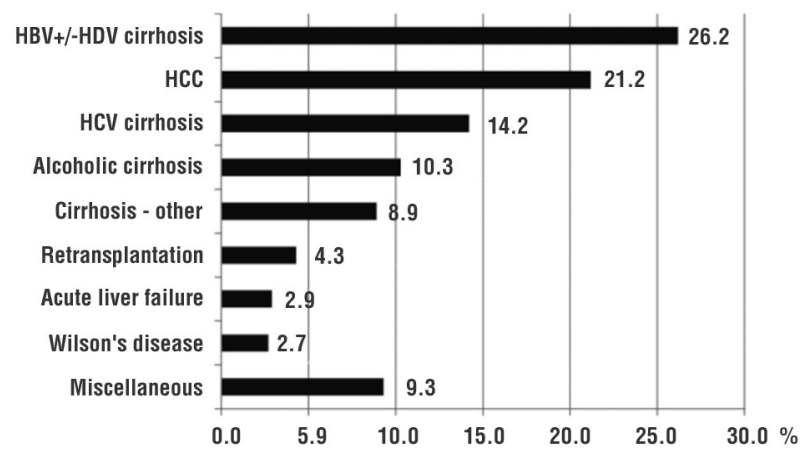

Figure 2 - Indication for LT in the overall group 


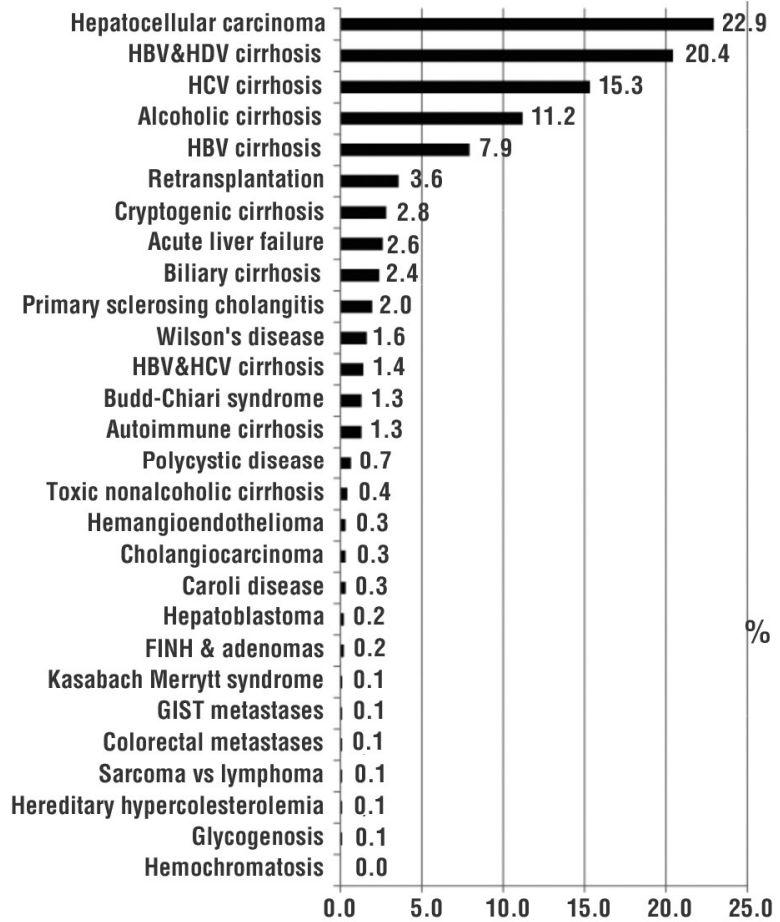

Figure 3 - Indication for LT in adult patients

living donor with homozygous familial hypercholesterolemia that was transplanted in a recipient with HCC on cirrhosis, while the first patient received an extended right hemiliver as split LT. For the auxiliary LT, we used a left lateral section coming from a splited graft (the other partial graft was allocated to another center). For the 167 LDLT recipients, we used 121 right hemilivers, 28 left lateral sections, 9 left hemilivers, 6 left hemilivers plus segment 1 ; 6 donors donated for 3 dual graft LDLTs. The LDLT procedures in adult and pediatric programs are

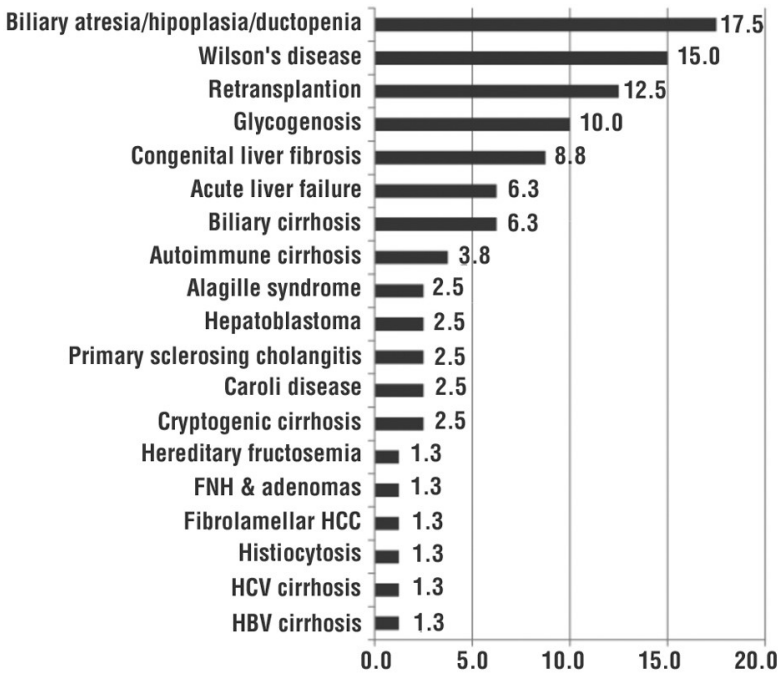

Figure 4 - Indications for LT in pediatric patients (\%)

showed in table 1 and table 2. Dual graft LDLT was performed in 3 recipients: 2 recipients received a right hemiliver and a left lateral section each, while the third recipient received a left hemiliver and a left lateral section. The types of LT used for both adult and pediatric programs are showed in table 2. The technical features of both DDLT and LDLT (cold and warm ischemia times, operative time, and intraoperative blood loss) are showed in table 3.

\section{Postoperative results}

Fig. 7 shows the distribution per year of the LT procedures. The major morbidity rates in the overall, DDLT, and LDLT series were $42.2 \%$ (422 out of $1000 \mathrm{LTS}$ ), $38.5 \%$ (320 out of 831 LTs) and $60.3 \%$ (102 out of 169 LTs), respectively $(p<0.01)$. Moreover, the major

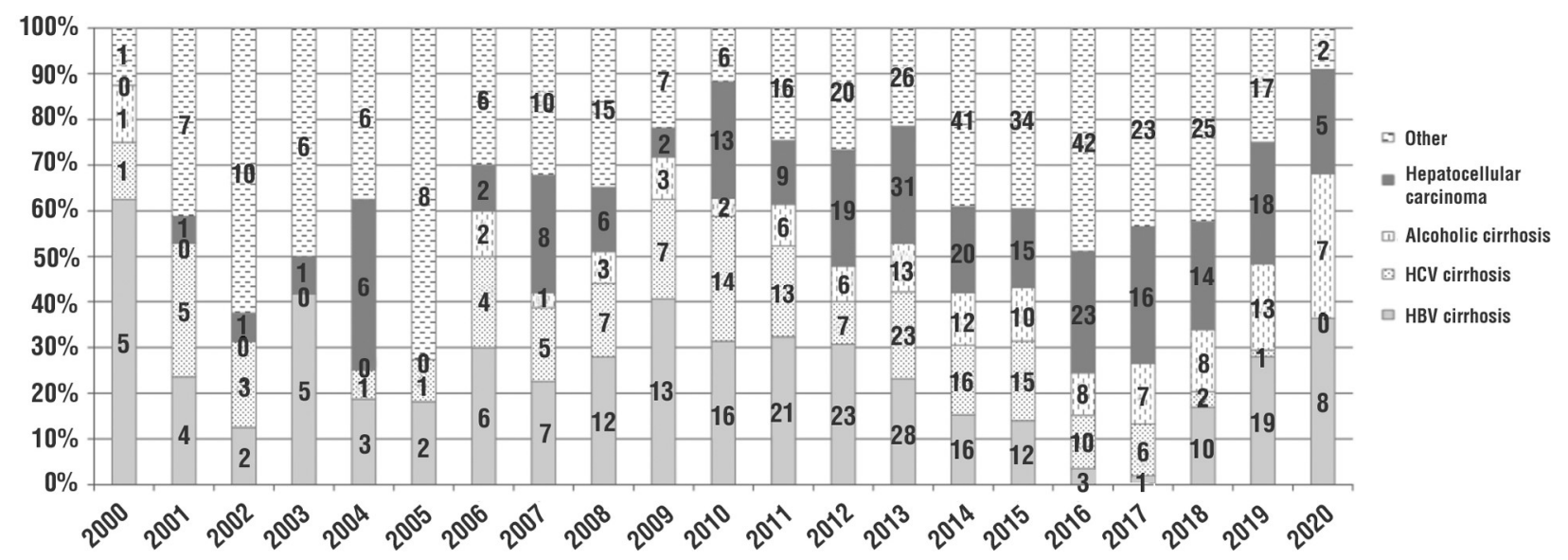

Figure 5 - Evolution of main indications for LT in the overall group 
Table 1 - Type of procedures

\begin{tabular}{lcc}
\hline & LT types & Patients \\
\hline Deceased donor LT & $\mathbf{8 3 1}$ & $\mathbf{7 9 0}$ \\
\hline Whole liver DDLT & 804 & 769 \\
$\quad$ adult & 782 & \\
$\quad$ pediatric & 22 & \\
\hdashline Split LT & 20 & 17 \\
$\quad$ Ex-situ & 7 & \\
$\quad$ In-situ & 3 & \\
$\quad$ Extended right hemiliver and left lateral section & 8 & \\
Right and left hemiliver & 2 & \\
\hdashline Reduced-size LT & 5 & 2 \\
\hdashline Domino LT & 1 & 1 \\
\hdashline Auxiliary LT & 1 & 1 \\
\hdashline Living donor LT & 1 \\
LDLT & 169 & $\mathbf{1 6 7}$ \\
$\quad$ adult & 166 & 164 \\
pediatric & 122 & 122 \\
\hline Dual LDLT & 44 & 42 \\
\hline TOTAL & 3 & 3 \\
\hline
\end{tabular}

Table 3 - Comparative operative parameters of recipients of deceased (DDLT) and living (LDLT) donor liver transplantation

\begin{tabular}{lcc}
\hline Parameters (mean and SD) & $\begin{array}{c}\text { DDLT } \\
\text { (N=790) }\end{array}$ & $\begin{array}{c}\text { LDLT } \\
\text { (N=167) }\end{array}$ \\
\hline Age (year) & $42 \pm 16$ & $34 \pm 25$ \\
\hdashline Gender (M/F) & $487 / 303$ & $79 / 88$ \\
\hdashline Operative time (min) & $381 \pm 104$ & $472 \pm 127$ \\
\hline Cold ischemia time (min) & $550 \pm 407$ & $142 \pm 59$ \\
\hline Warm ischemia time (min) & $37 \pm 27$ & $52 \pm 32$ \\
\hline Blood loss (I) & $5.5 \pm 7.9$ & $6.3 \pm 9.9$ \\
\hline
\end{tabular}

morbidity rates in the 3 historical groups were $55 \%$ ( 55 out of 100 LTs), $48.4 \%$ (76 out of 157 LTs), and $39.2 \% \%$ (291 out of 743 LTs), respectively ( $p=0.017$ ), while the
Table 2 - LT types used in the adult and pediatric programs

\begin{tabular}{lcccc}
\hline & \multicolumn{2}{c}{ LT types } & \multicolumn{2}{c}{ Patients } \\
\hline & Adult & Pediatric & Adult & Pediatric \\
\hline Deceased donor LT & $\mathbf{7 9 6}$ & $\mathbf{3 5}$ & $\mathbf{7 6 3}$ & $\mathbf{2 7}$ \\
\hline Whole liver DDLT & 782 & 22 & 750 & 19 \\
\hdashline Split LT & 11 & 9 & 10 & 7 \\
$\quad$ Left lateral section & 0 & 8 & 0 & 6 \\
Left hemiliver & 2 & 0 & 2 & 0 \\
Right hemiliver & 1 & 1 & 1 & 1 \\
Extended right hemiliver & 8 & 0 & 7 & 0 \\
\hdashline Domino LT & 1 & 0 & 1 & 0 \\
\hdashline Auxiliary LT & 1 & 0 & 1 & 0 \\
\hdashline Living donor LT & 124 & $\mathbf{4 5}$ & $\mathbf{1 2 4}$ & $\mathbf{4 3}$ \\
\hline LDLT & 122 & 44 & 122 & 42 \\
Left lateral section & 0 & 30 & 0 & 28 \\
Left hemiliver & 3 & 6 & 3 & 6 \\
Left hemiliver and S1 & 4 & 2 & 4 & 2 \\
Right hemiliver & 115 & 6 & 115 & 6 \\
\hdashline Dual LDLT & 2 & 1 & 2 & 1 \\
\hline TOTAL & 920 & 80 & 887 & 70 \\
\hline
\end{tabular}

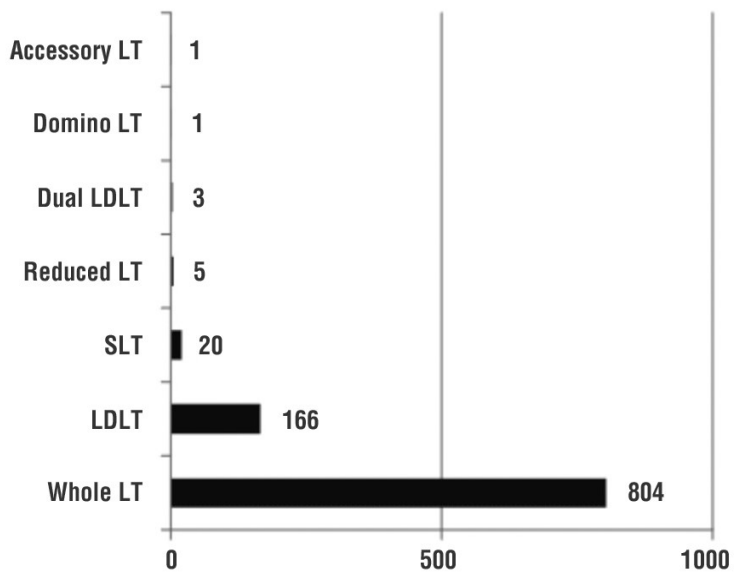

Figure 6 - Surgical techniques used for LT in the overall group (number of pts)

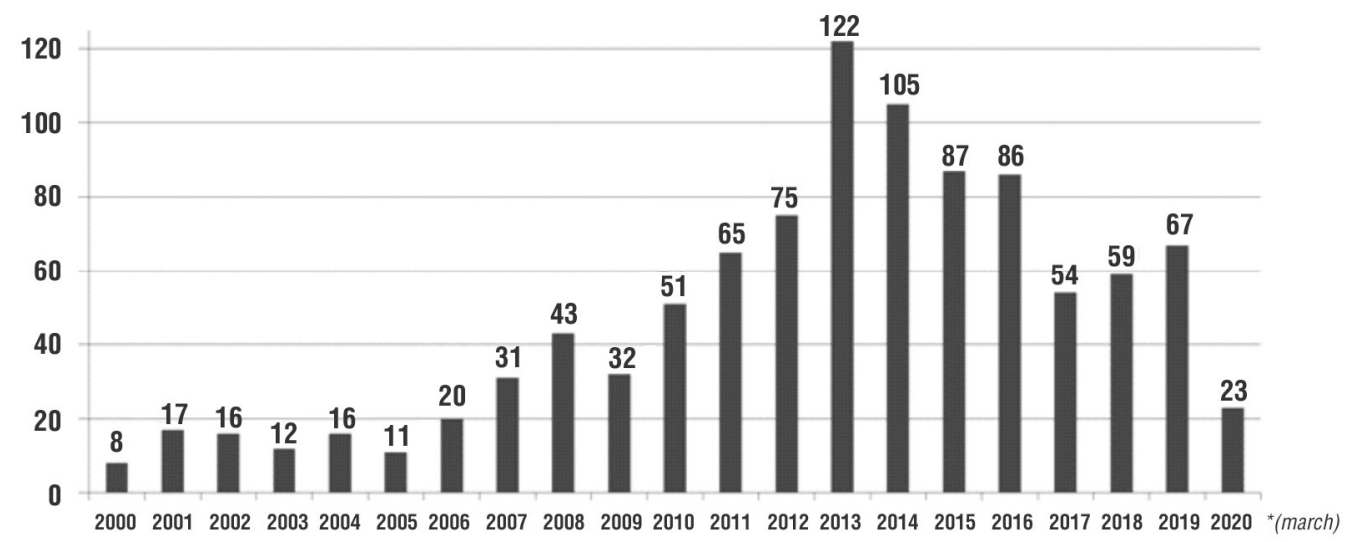

Figure 7 - Year distribution of LT number 
mortality rates were $11.5 \%$ (11 out of 96 pts), $8.1 \%$ (12 out of 148 pts), and $7.9 \%$ (56 out of 713 pts), respectively $(p=0.078)$.

The retransplantation rates in the overall, DDLT and LDLT series were $4.5 \%$ (43 pts), 3.4\% (27 out of 790 pts), and $9.6 \%$ (16 out of 167 pts), respectively $(p<0.01)$ (table 4). In the DDLT series, the 27 procedures that needed retransplantation were: 25 whole graft LTs, 1 reduced-size LT and 1 auxiliary LT. In the LDLT series, the 16 procedures that needed retransplantation were: 5 LDLTs with left lateral section, 1 LDLT with left hemiliver, 9 LDLT with right hemiliver, and 1 dual graft LDLT (with right hemiliver and left lateral section).

In the 43 retransplanted patients we used 41 DDLTS $(95,3 \%)$ and 2 LDLTs $(4,7 \%)$. For the 41 retransplanted patients using DDLT, we used: 35 whole grafts, 3 reduced-size grafts, 3 split grafts ( 2 left lateral sections, and 1 right hemiliver). These patients were initially transplanted using 26 DDLTs (24 whole grafts, 1 reduced-size graft, and 1 auxiliary LT) and 15 LTLD (4 left lateral sections, 1 left hemiliver, 9 right hemilivers, and 1 dual graft LDLT). For the 2 retransplanted patients using LDLT, we used 2 left lateral sections from living donors for patients initially transplanted using LDLT with left lateral section, and whole DDLT, respectively. The LT procedures used in the retransplanted adult and pediatric patients are showed in table 5 .

The perioperative mortality rate in the overall, DDLT, and LDLT series were $8.3 \%$ (79 out of $957 \mathrm{pts}$ ), 7.1\% (56 out of 790 pts) and $13.8 \%$ ( 23 out of 167 pts), respectively $(p=0.033)$.

Median follow-up was 59 months (mean 65, range 5-250). The overall estimated survival rates of patients at $1-, 3-,-5$ and 10 -year were $82.3 \%, 77.8 \%, 76.3 \%$ and $71.2 \%$, respectively. Male vs female long-term 1-, 3-, -5 and 10-year estimated survival rates were $90.1 \%$, $84.3 \%, 82.1 \%$ and $76.2 \%$ (males), and $88.8 \%, 85.6 \%$, $84.9 \%$ and $80.8 \%$ (females), respectively $(p=0.28)$. In pediatric vs adult patients, the long-term $1-, 3-,-5$ and 10-year estimated survival rates were $94.2 \%, 90.2 \%$, $90.2 \%$ and $78.4 \%$ (0-17 yrs.), and $89.3 \%, 84.5 \%, 82.8 \%$ and $78.3 \%$, respectively $(\mathrm{p}=0.55)$.

The long-term 1-, 3-, -5 and 10-year estimated survival rates in HBV-related cirrhosis, HCV-related cirrhosis, alcoholic cirrhosis, and HCC were: 93.1\%, 90.1\%, 88.1\%, 86.7\% and 86.7\%; 83.5\%, 78.6\%, 77.6\%, and $70.9 \% ; 90.5 \%, 86.6 \%, 84.9$ and $82.2 \% ; 89.4 \%$, $77.8 \%, 74.7 \%$, and $71.5 \%$, respectively ( $\mathrm{p}=0.013$ ) (fig. 8).

The longest survival is the first successfully transplanted patient (a 46-yr old male transplanted in
Table 4 - Procedures used in the retransplanted patients $(N=43)$

\begin{tabular}{lcc}
\hline & LT requiring reLT & ReLT procedure \\
\hline Deceased donor LT & $\mathbf{2 7}$ & $\mathbf{4 1}$ \\
\hline Whole liver DDLT & 25 & 35 \\
$\quad$ adult & 23 & 32 \\
$\quad$ pediatric & 2 & 3 \\
\hline Split LT & 0 & 3 \\
\hline Reduced-size LT & 1 & 3 \\
\hline Auxiliary LT & 1 & \\
\hdashline Living donor LT & $\mathbf{1 6}$ & $\mathbf{2}$ \\
\hline LDLT & 15 & 2 \\
$\quad$ adult & 15 & 0 \\
pediatric & 0 & 2 \\
\hdashline Dual LDLT & 1 & 0 \\
\hline
\end{tabular}

April 2000 with a whole graft for HBV cirrhosis), who is alive and well after almost 21 years.

In the low-, mid- and high-volume center groups, the long-term 1-, 3-, -5 and 10-year estimated survival rates were $78.8 \%, 73.8 \%, 72.5 \%$ and $63.8 \%$ (Group 1 ), $92.6 \%, 85.3 \%, 80.9 \%$ and $75.6 \%$ (Group 2), and $89.7 \%$, $85.3 \%, 84.4 \%$ and $83.2 \%$ (Group 3), respectively $(\mathrm{p}=0.006)$ (fig. 9).

\section{Donors}

For the 957 recipients, we retrieved grafts from 992 donors.

\section{Deceased donors}

We retrieved 831 grafts from 820 deceased donors, with a median donor age was 44 yrs. (mean 41; range 2-78), and male/female ratio was 533/287. The blood types were: 0 in 286 donors (34.9\%), All in 353 donors (43\%), BIII in 123 donors (15\%), and ABIV in 58 donors (7.1\%).

Table 5 - The initial and the retransplantation LT types used in adult and pediatric programs

\begin{tabular}{lcccc}
\hline & \multicolumn{2}{c}{ LT requiring reLT } & \multicolumn{2}{c}{ ReLT procedure } \\
\hline & Adult & Pediatric & Adult & Pediatric \\
\hline Deceased donor LT & $\mathbf{2 4}$ & $\mathbf{3}$ & $\mathbf{3 3}$ & $\mathbf{8}$ \\
\hline Whole liver DDLT & 23 & 2 & 32 & 3 \\
\hdashline Split LT & 0 & 0 & 1 & 2 \\
\hline Reduced-size LT & 0 & 1 & 0 & 3 \\
\hdashline Auxiliary LT & 1 & 0 & 0 & 0 \\
\hline Living donor LT & $\mathbf{9}$ & $\mathbf{7}$ & $\mathbf{0}$ & $\mathbf{2}$ \\
\hline LDLT & 8 & 7 & 0 & 2 \\
\hline Dual LDLT & 1 & 0 & 0 & 0 \\
\hline TOTAL & 33 & 10 & 33 & 10 \\
\hline
\end{tabular}




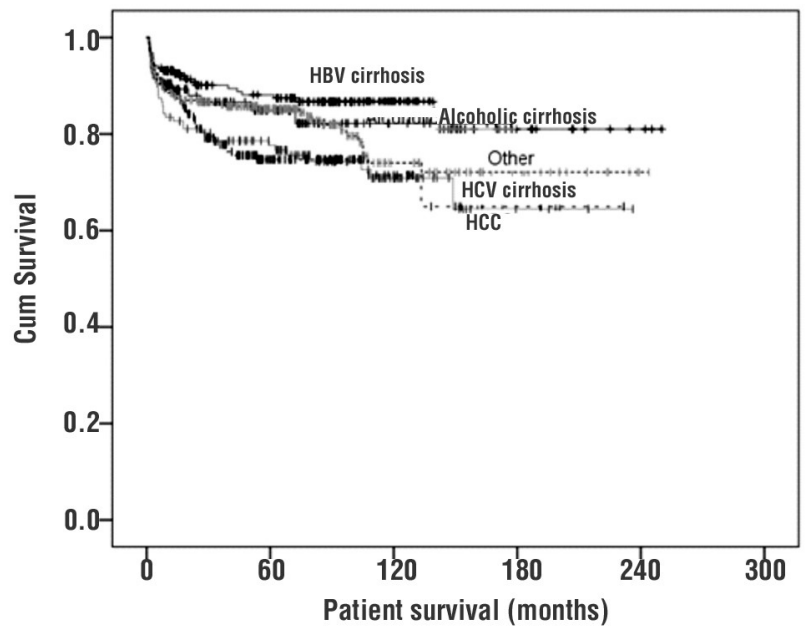

Figure 8 - Long-term survival according to the indications for liver transplantation (LT) $(p=0.013)$

Of these, 780 grafts were allocated for whole LT, 8 whole (splited) grafts and 1 partial graft (extended right hemiliver) for split LT, 2 whole grafts for reduced LT, and 1 whole graft for domino LT. For retransplantation, we allocated 35 grafts for whole reLT, 3 grafts for reducedsize reLT, and 2 left lateral sections and 1 extended right hemiliver for 3 split reLT.

Most of the deceased donors had the age between 18 and 45 yrs. (370 donors; $44.5 \%$ ). Stroke was the main cause of death (387 donors; $47.3 \%$ ), with an incidence that increased with time, followed by cerebral trauma (372 donors; 44.9\%) (fig. 10). Other causes (61 donors; 7.5\%) were asphyxiation (19 donors), cerebral tumor (3

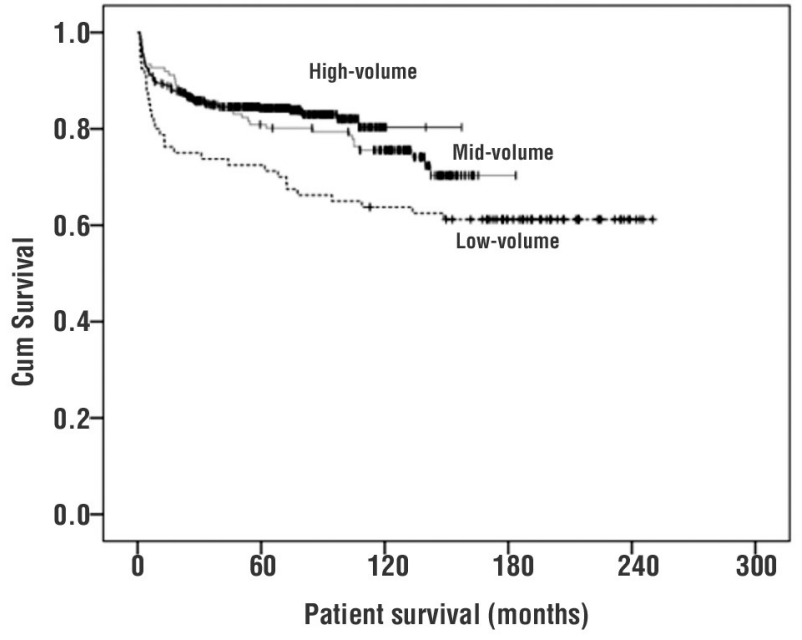

Figure 9 - Patient survival during the 3 periods of the main center development (low-, mid-, and high-volume center) $(p=0.06)$

donors), resuscitated cardiac arrest (20 donors), intoxication (16 donors), and acute hydrocephalus (3 donors).

The overall, adult, and pediatric median whole graft weight were $1580 \mathrm{~g}$ (mean 1577; range 3003150), $1600 \mathrm{~g}$ (mean 1600; range 638-3150), and 920 g (mean 660; range 230-1640), respectively. The median split graft weight was $600 \mathrm{~g}$ (mean 750; range 230-1750). The median cold and warm ischemia times were 5:47 $\mathrm{h}$ (mean 9:10; range 1:20 - 16:41) and 0:31 h (mean 0:37; range 0:05 - 05:38), respectively.

Out of the 804 grafts used for whole graft DDLT, 412 were ECD grafts (54.3\%). Out of these, 151 ECD

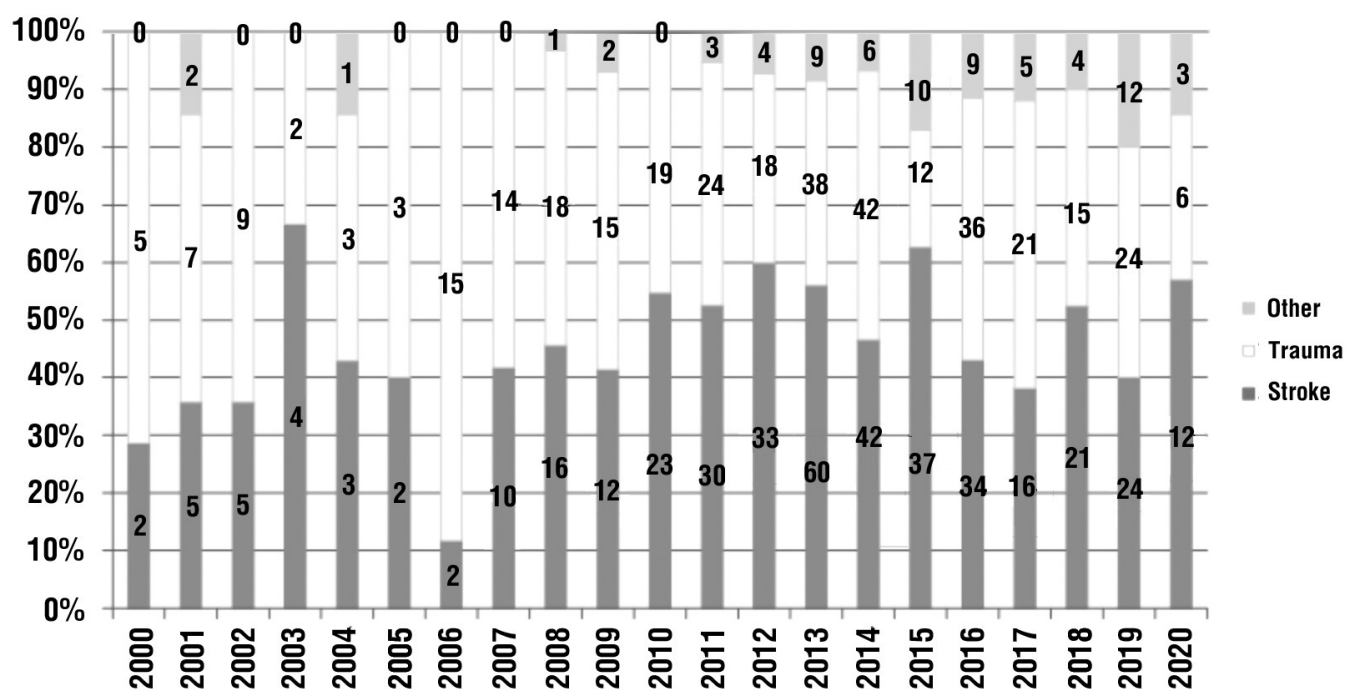

Figure 10 - Evolution of causes of death in donors 
grafts (36.6\%) had multiple criteria (table 6).

We also used particular sources of liver grafts (17 pts; 2\%): methanol-poisoning (4 donors), liver graft trauma (10 donors), benign tumors in liver graft (3 donors) and Takayasu's syndrome (1 donor).

\section{Hypothermic oxygenated mechanical perfusion} of liver grafts

We applied the hypothermic oxygenated mechanical perfusion on 14 ECD liver grafts. In 4 grafts we applied dual HOPE, while in the other 10 grafts we applied the single HOPE. There were no complications related to liver function in the transplanted patients, except in one case who developed artery thrombosis (the artery of the graft was not mechanically perfused in this case). The perfusion time varied between 1:50 minutes and 5:10 hours, the main monitored parameter being the lactate, with a threshold of $3 \mathrm{mmol} / \mathrm{L}$.

\section{Living donors}

We retrieved grafts from 172 living donors (17.1\% of total number of donors): 121 right hemilivers (12.6\%), 30 left lateral sections (2.9\%), 9 left hemilivers (0.9\%), 6 left hemilivers with segment $1(0.6 \%)$, and 6 partial grafts for 3 dual graft LDLT (0.6\%). Out of these, 2 left lateral sections were used for retransplantation.

The overall median age of the living donors was 33 yrs. (mean 34; range 19-53), and male/female ratio was 74/98. The donor blood types were: 01 in 69 donors (40.1\%), All in 68 donors (39.5\%), Blll in 23 donors (13.4\%), and ABIV in 12 donors (7\%). Most donors were between 18 and 45 years old ( $\mathrm{N}=153 ; 89 \%)$, with a male/female ratio of $69 / 84$. Major complication rate was
$2.9 \%$ (5 pts), with a reoperation rate of $2.3 \%$ ( $4 \mathrm{pts}$ ), and no mortality.

The median graft weight was $700 \mathrm{~g}$ (mean 656; range 180-1300). The median cold and warm ischemia periods were 131 min (mean 142; range 53 - 347) and 49 min (mean 52; range 3 - 171), respectively.

\section{Donor-recipient matching}

For urgent LT, 12 recipients underwent $A B O-$ incompatible LT for acute liver failure (8 patients), and urgent retransplantation for primary graft nonfunction ( 3 patients) and hepatic artery thrombosis (1 patients). For these recipients, we performed 11 DDLTs and 1 LDLT. 90-day survival was $84 \%$. The desensitization protocol included a single dose of rituximab in two patients and plasma exchange in all patients. Plasma exchange was performed both before liver transplantation and in consecutive sessions during the early postoperative period to lower ABOantibodies titre. In order to rebalance the severe inflammatory response associated with both acute liver failure and graft non-function consecutive sessions consisting of hemodiafiltration and hemoadsorbtion were applied during the perioperative period.

\section{DISCUSSION}

LT is a well-established treatment providing significant longer survival and improved quality of life when compared to other methods. Of note, the lengthiest post-LT survival recorded is 42 years (30).

The number of LTs continuously rises worldwide. For example, in 2012 were recorded 23,986 LTs,

Table 6 - Extended criteria for liver grafts $(\mathrm{N}=412)$

\begin{tabular}{|c|c|c|}
\hline & Extended criteria for liver grafts & No of pts \\
\hline Donor-related features: & $\begin{array}{l}\text { Age }>65 \text { yrs. } \\
\text { Body mass index }>30 \mathrm{~kg} / \mathrm{m}^{2}\end{array}$ & $\begin{array}{l}37 \\
24\end{array}$ \\
\hline Factors related to ICU: & $\begin{array}{l}\text { ICU stay and ventilation support }>7 \text { days } \\
\text { Hypotension and inotropic support ( } \geq 2 \text { pressors at any time, high-dose dopamine or epinephrine) } \\
\text { Resuscitated cardiac arrest }\end{array}$ & $\begin{array}{c}59 \\
136 \\
113\end{array}$ \\
\hline Liver steatosis: & Macrosteatosis $(>30 \%$ but $\leq 60 \%)$ & 64 \\
\hline Biochemical imbalances: & $\begin{array}{l}\text { Hypernatremia (peak serum Na >165 mEq/L) } \\
\text { Liver disfunction (AST/ALT>3X; BT > } 3 \mathrm{mg} / \mathrm{dl} \text { ) }\end{array}$ & $\begin{array}{l}45 \\
32\end{array}$ \\
\hline Cold ischemia time & $>12$ hours & 1 \\
\hline Viral infections: & $\begin{array}{l}\text { Positive serology for HBV hepatitis } \\
\text { AgHBs (+) } \\
\text { AgHbc (+) } \\
\text { Positive serology for HCV hepatitis }\end{array}$ & $\begin{array}{c}18 \\
6 \\
11 \\
1\end{array}$ \\
\hline Sepsis-related factors: & Sepsis with positive blood culture & 4 \\
\hline Malignancy risk factors: & History of extrahepatic malignancy & 1 \\
\hline Non-heart beating donors & & 1 \\
\hline
\end{tabular}


while in 2018 - 34,074, with an increase of 5\% when compared to 2017 (31). Romania started the LT program as a stringent requirement in 2000 , while in Europe over 4,500 procedures were recorded that year, and almost 45,000 worldwide (32).

\section{Waiting list}

The number of patients on the WL for LT has continuously increased over the past decade, mainly because of the lack of organs, with consequent increased mortality rate on the waiting list, lengthy waiting time, and paucity of supply for urgent LT (33) (34). In US, approximately 10,000 patients are enrolled each year on the WL, with around 15,000 patients still waiting for LT by the end of the given year. In Romania, the number of patients enrolled on the WL has constantly increased over time, with 468 patients listed in 2019. However, 1- and 3-year mortality on WL diminished significantly over time, from $25 \%$ and $46 \%$ (in the interval 2000-2010), respectively, to $18 \%$ and $29 \%$ (in the interval 2017 2020), respectively $(p<0.0001)$. Despite the increase in LT number, the mortality on the waiting list remains between $5 \%-10 \%$ worldwide (34), while in Romania varied from $13 \%$ to $25 \%$. Generally, patients must cope with long times on the WL. Our main goal was to decrease the mortality and drop-out rates on the $\mathrm{WL}$ by reducing the waiting time for $\mathrm{LT}$.

\section{Recipients}

LT has become a recognized lifesaving treatment that grew from an experimental procedure retained for desperately ill patients. Nevertheless, many features related to LT indication, surgical techniques, infectious complications, and immunosuppressive treatment are still to be fully assessed, and vary significantly between transplant centers.

In our experience, HBV-related cirrhosis was the leading indication for LT. In Western countries, HCVrelated cirrhosis declined in prevalence in patients aged $18-50$ years, leading to a significant decrease in WL enrollment (35). Nowadays, nonalcoholic fatty liver disease (NAFLD) is the most common cause for chronic liver disease in developed countries and will most likely grow to be one of the main indications for LT in the United States $(36,37)$.

Recipient's age has increased in the last decade, with around $30 \%$ of the patients on the $\mathrm{WL}$ and ultimately transplanted were over 60 years old. Elderly recipients generally have a weaker immune system, with consequent reduced need for immunosuppressive treatment, and probably lower incidence of acute allograft rejection. Despite good overall postoperative survival, long-term survival may be impaired by complications not necessarily related to transplantation, such as malignancy and vascular disease (38). In our experience, $12.6 \%$ of recipients (121 pts) were over 60 years old. The recipient's age increased during the analyzed period, in agreement with the literature data: Group 3 had a higher mean age compared to Group 1 (46 yrs. vs 36 yrs., respectively; $p=0.031$ ).

Since the first successful DDLT performed by Starzl TE (USA) in 1967 (1), whole organ LT remains the main procedure in LT. However, the necessity to boost the number of LTs, despite the deceased donor's shortage, lead to implementing other techniques, such as LDLT, split graft LT, and domino LT.

LDLT represents one of the most remarkable steps in pediatric LT in particular, and in LT in general. It was first described in 1969 (39), but introduced much later, in 1989 (6). LDLT uses a unique source of grafts, addressed to a specific candidate, with no need for an allocation system. In Europe, LDLT represents around $4 \%$ (32) of all LT procedures, while in US - around $22 \%$ (40), and in Asia (except China) - over 90\% (41). For pediatric recipients, LDLT has become the main source of donors, while in adults represents a good indication in selected cases. Advantages of this procedure comprise the facility to be performed electively, with optimal timing and no waiting time, with a graft in excellent state (carefully selected graft, healthy young donor), with short ischemic time, while the indications may be extended (i.e., HCC beyond Milan criteria). As drawbacks, LDLT involves donor mortality, even though as low as $0.5-1 \%(42)(43)$, higher rates of vascular (5-15\%) and biliary (10-30\%) complications, and risk of small-for-size syndrome in both donor and recipient (44). These drawbacks, especially the donor mortality, had led to a drastic decrease of LDLT number, mainly in the Western countries, after the initial boost. In contrast, we maintained and continuously developed the living program, considering it a very important part of our LT program. Recently, even the Western countries started to reconsider the LDLT due to the huge success and excellent results of the programs in the Far East (South Korea, Hong Kong, Japan, Taiwan) and Turkey (45).

Despite higher postoperative complication rate when compared to DDLT, with proper treatment the long-term outcome may be similar (46). Although complex and expertise demanding, dual graft LDLT 
has proven to be a safe procedure and a feasible solution to overcome the risk of small-for-size graft syndrome, when the selection of an optimal single donor fails $(18,47,48)$. Even though we performed only 3 cases, it remains part of our strategy to increase the number of LTs.

Split graft LT demands a liver with normal anatomy and function. Currently, split LT represents only around $5 \%$ of total LTs, but up to $20 \%$ of donors are actually potential candidates, hence the necessity of proper identification and harvest (49). In-situ split LT may provide comparable long-term survival results with those for whole liver LT, even though with a higher incidence of biliary and vascular complications (50). The drawbacks of ex-vivo split LT include time-consuming procedure, prolonged cold ischemia time, increased ischemia-reperfusion injury, poor graft function, while for in-situ split LT the drawbacks are lengthy retrieval time and necessity for more expertise.

Domino $\mathrm{LT}$, although rare, remains a viable alternative in selected cases with hereditary metabolic disease, such as familial amyloidotic polyneuropathy and homozygous familial hypercholesterolemia $(19,51,52,53)$.

Auxiliary LT emerged as a technical variant for LT from the concept based on the potential for spontaneous regeneration of the native liver and eventual withdrawal of immunosuppressive drugs. A significant minority of patients with ALF who fulfil transplant criteria would have had complete morphological and functional recovery of their native liver if they had not undergone OLT. The favorable outcome reported in European series using auxiliary partial orthotopic liver transplantation (APOLT) and the expertise gained from SLT and LDLT have revived the interest in this approach (54).

We improved our results over time, in terms of operative key factors (i.e., cold and warm ischemia time, operative time and blood loss), major morbidity and postoperative results. The major morbidity and perioperative mortality rates decreased significantly from $57.3 \%$ and $11.5 \%$ in Group 1 (low-volume center period) to $40.7 \%$ and $7.9 \%$ in Group 3 (high-volume center period), respectively $(p=0.041$ and $p=0.056$, respectively).

In our series, the overall long-term 1-, 3-, and 5-year estimated survival rates were like the one reported by ELTR (55) and OPTN/SRTR (35): 89\% at 1 year and $75 \%$ at 5 years. The long-term results also significantly improved over time, mainly in Group 2 and 3 (mid- and high-volume center periods) compared to Group 1 (low-volume center period), with 1-, 3-, and 5-year estimated survival rates of 78.8.1\%, 73.8\%, and 71.3\% (Group 1), 92.6\%, 85.3\%, and $80.9 \%$ (Group 2), and $89.7 \%, 85.3 \%$, and $84.4 \%$ (Group 3), respectively $(p=0.06)$.

\section{Donors}

Cadaveric donors account for most liver grafts (over $90 \%$ in Europe and China). However, but this resource is severely limited by social, cultural, or legal factors. Romania is the Vth among Eastern European countries, with a donation rate of $6.1 \mathrm{pmp}$ (32). About $75-80 \%$ of donors provide a liver for LT.

During early 1990s, severe cerebral trauma after traffic crashes represented the main cause of death for donors worldwide, decreasing progressively over time and currently replaced by stroke. A similar trend was recorded in Romania, with a decrease of trauma incidence from $65.1 \%$ in Group 1 (44 out of 67 deceased donors) to $38.4 \%$ in Group 3 (236 out of 614 deceased donors) $(p=0.012)$, and a concomitant increase of stroke incidence from 34.3\% in Group 1 (23 out of 67 deceased donors) to $50.3 \%$ in Group 3 (309 out of 614 deceased donors) $(p=0.031)$.

In our early experience, we avoided donors over 65 yrs., but we accepted them over time $(1.5 \%$ and $8.1 \%$ in Group 2 and 3, respectively). Spain and Italy have the highest percentage of over 70-year donors in Europe, representing over $20 \%$ of total donors (56).

The use of extended criteria grafts has become a common policy worldwide because of organ shortage. The boundaries of extended criteria were continuously pushed, and organs previously deemed improper for LT are nowadays accepted for transplantation. However, presence of multiple extended criteria appears to adversely impact on graft function (57). Development and implementation of methods to avoid and/or treat the ischemia/reperfusion graft injuries, such as the graft machine perfusion, represents the key to further push the limits of extended criteria while improving the LT outcome (58). HBVpositive organs are no longer a contraindication for LT. Also, the new effective antiviral drugs have made more HCV-positive organs available (35).

Aggressive usage of extended donors and reducedsize, split, and living-related liver transplantation continues to expand the organ donor pool, though these efforts still fail to meet the need for organs. Additional sources for liver grafts, such as methanolpoisoned donors, grafts with trauma lesions, benign tumors, or certain rare conditions (e.g., Takayasu's 
syndrome), even though rare, represent a source for grafts that should not be neglected.

Recently, there has been a steady increase of living donors worldwide, mainly because of the lack of deceased donors. In 2018, LDLT represented 19\% of all LTs (31). A similar trend was recorded in Romania: Group 3 included $67.1 \%$ (112 pts) of all 167 LDLT, while Group 1 and 2 included only 17.9\% (30 pts), and 16.1\% (27 pts), respectively.

In terms of organ retrieval, preservation and transportation, major improvements are being made worldwide, as in our country, to optimize distribution and to ensure suitable matches.

\section{Hypothermic oxygenated mechanical perfusion of liver grafts}

Static cold storage, the main method of preservation, causes injury to the liver graft. The liver reperfusion after ischemia is responsible for the hepatocellular damage and liver failure (59). The main modifications are destruction of sinusoidal endothelial cells, sinusoidal constriction, inflammatory reaction, platelet aggregation and formation of microthrombi.

The machine perfusion comes as an alternative to the static cold storage, and it improves the quality of marginal grafts. It provides nutrients to the liver, removes toxic substances, restores mitochondrial function by oxygenated MP, resulting in an increased adenosine triphosphate (ATP) tissue concentration while adequately oxygenating the graft. Preliminary clinical results showed less biliary complications, short ICU stay and shorter hospital stay in comparison to patients receiving a liver preserved only with static cold storage $(60,61)$, findings that are to be confirmed in a multicenter randomized clinical trial in which our center will take part.

We introduced this graft therapy method in Romania in 2016 with good results. We are very confident that this method will continuously increase its use worldwide and will become a standard procedure for improving quality at least in ECD grafts, thus significantly decreasing the posttransplant complications.

\section{ABO-incompatible liver transplantation}

The lack of organs has led to the implementation of anti-A/B antibody reducing immunosuppressive protocols, with similar results compared to ABOcompatible LT: 3-year graft survival rate of $91 \%$ vs $90 \%$, respectively (62). The application of these protocols is extensively studied in LDLT, while in LDLT the experience is still limited (63). The major complication after ABO-incompatible LT remains the delayed antibody-mediated rejection, consisting in intrahepatic biliary strictures which seems to be similar to the nonanastomotic biliary strictures associated with DDLT. Since the machine perfusion seems to reduce the risk for the latter (64), this procedure may be taken into consideration as part of the ABOincompatible protocol. However, whether the biliary complications in ABO-incompatible LT and nonanastomotic biliary strictures after DDLT have the same pathophysiological mechanisms remains to be determined.

\section{Policy}

Our main strategy to increase the number of LTs was based on the expansion of the donor pool by improving the organ donation laws, training the medical professionals, mass education, and by optimizing the donor hospital protocols (15). The use of deceased donors was maximized by ECD grafts and use of other sources for liver grafts, such as poisoned donors (methanol) and grafts with certain lesions (trauma, benign tumors, etc.). Technical variant grafts, such as LDLT, split LT, dual graft LT, auxiliary LT and domino LT, were also used to further increase the number of LTs. Despite our efforts, the number of LTs significantly decreased in the last 5 years, mainly because of administrative issues. Of note, the analyzed period coincidentally finishes roughly when the COVID pandemic started, event that further decreased the number of LTs.

\section{CONCLUSION}

In conclusion, a combined cadaveric and living donor LT program is resourceful, offering all surgical variant LT procedures (LDLT, split LT, dual LDLT, auxiliary and domino LT). The increase of both deceased and living donors is mandatory to significantly extend the donor pool. Various strategies are recommended to expand the donor pool and increase the number of LTs, including the use of extended criteria donors, and of the variant LT techniques. Optimal donor-recipient matching is the key for the proper use of marginal and surgical variant grafts. However, ABO-incompatible LT remains a useful strategy for insuring urgent LT.

Multi-disciplinary approach is the main feature of a LT program, that involves many disciplines like surgery, imaging, endoscopy, interventional radiology, micro- 
biology, pathology, psychology, etc.

A combined program of cadaveric and living donor liver transplantation uses all sources of liver grafts, contributes to expertise buildup, and quickens the development to high volume center. In this way, it reduces the mortality on the waiting list, waiting time for $\mathrm{LT}$, and overall postoperative results.

Patients with immediate need for LT (acute liver failure, retransplantation) are offered best chance for transplantation in a combined cadaveric and livingrelated program. A modern liver transplant center achieves this goal by offering its patients all liver transplant techniques available, independent of the donor type.

New challenges are to be faced to maintain and to further develop this program, in the context of socioeconomic crisis.

\section{Conflicts of interest and source of funding}

No source of funding support are reported for the paper.

\section{Ethical approval}

The study was approved by the Ethics Committee.

\section{REFERENCES}

1. Starzl T E, Groth C G, Brettschneider L, Penn I, Fulginiti V A, Moon, et al. Orthotopic homotransplantation of the human liver. Ann Surg 1968;168:392-415.

2. Calne RY, Williams R. Liver transplantation in man-I, observations on technique and organization in five cases. Br Med J 1968;4: 535-540.

3. Hamilton D, Barker CF, Starzl TE. A History of Organ Transplantation: Ancient Legends to Modern Practice. Pittsburgh, Pa.: University of Pittsburgh Press, 2012.

4. Raia S, Nery JR, Mies S. Liver transplantation from live donors. Lancet. 1989;2(8661):497.

5. Strong RW, Lynch SV, Ong TH, Matsunami H, Koido $\mathrm{Y}$, Balderson GA. Successful liver transplantation from a living donor to her son N Engl J Med. 1990;322(21):1505-7.

6. Broelsch CE, Emond JC, Whitington PF, Thistlethwaite JR, Baker AL, Lichtor JL. Application of reduced-size liver transplants as split grafts, auxiliary orthotopic grafts, and living related segmental transplants. Ann Surg. 1990; 212(3):368-75; 375-7.

7. Kawasaki S, Makuuchi M, Matsunami H, Hashikura Y, Ikegami T, Nakazawa Y, et al. Living related liver transplantation in adults. Ann Surg. 1998;227(2):269-274.

8. Tanaka K, Inomata Y. Present status and prospects of livingrelated liver transplantation. J Hep Bil Pancr Surg. 1997;4:51-70.

9. Kim WR, Stock PG, Smith JM, Heimbach JK, Skeans MA, Edwards EB, et al. OPTN/SRTR 2011 annual data report: liver. Am J Transplant 2013;13(suppl 1):73-102.

10. Popescu I, Tulbure D, Ionescu M, Vasile R, Baila S, Ciurea S, et al. Liver transplantation--considerations over 8 cases operated in the year 2000. Chirurgia (Bucur). 2001;96(5):453-67.

11. Edwards EB, Roberts JP, McBride MA, Schulak JA, Hunsicker LG. The effect of the volume of procedures at transplantation centers on mortality after liver transplantation. N Engl J Med. 1999; 341:2049-2053

12. Axelrod DA, Kalbfleisch JD, Sun RJ, Guidinger MK, Biswas P, Levine GN, et al. Innovations in the assessment of transplant center performance: implications for quality improvement. Am J Transplant 2009;9(4 Pt 2):959-969.

13. McMillan RW, Uppot R, Zibari GB, Aultman DF, Dies DF, McDonald JC. Can low volume liver transplant centers be successful? The Regional Transplant Center of Willis-Knighton \& Louisiana State University Medical Center. The first 120 liver transplants. J La State Med Soc 1999, 151:367-372.

14. Guba M. Center volume, competition, and outcome in German liver transplant centers. Transplant Res. 2014;3(1):6.

15. Popescu I, Ionescu M, Brașoveanu V, Hrehoreț D, Copca N, Lupașcu C, et al. The Romanian National Program for Liver Transplantation - 852 Procedures in 815 Patients over 17 Years (2000-2017): A Continuous Evolution to Success. Chirurgia (Bucur). 2017;112(3):229-243.

16. Dindo D, Demartines N, Clavien PA. Classification of Surgical Complications: A New Proposal With Evaluation in a Cohort of 6336 Patients and Results of a Survey. Ann Surg. 2004;240(2):205-213.

17. Popescu I, Ionescu M, Brasoveanu V, Hrehoret D, Matei E, Dorobantu B, et al. Liver transplantation--indications, surgical technique, results--the analysis of a clinical series of 200 cases. Chirurgia (Bucur). 2010;105(2):177-86.

18. Botea F, Brașoveanu V, Constantinescu A, Ionescu M, Matei E, Popescu I. Living donor liver transplantation with dual grafts - a case report. Chirurgia (Bucur). 2013;108(4):547-52.

19. Popescu I, Simionescu M, Tulbure D, Sima A, Catana C, Niculescu $L$, et al. Homozygous familial hypercholesterolemia: specific indication for domino liver transplantation. Transplantation. 2003; 76(9):1345-50.

20. Popescu I, Ionescu M, Brasoveanu V, Hrehoret D, Botea F, Dorobanțu B, et al. Building a liver transplant program in a resource limited country: a 15-year retrospective analysis of 648 patients operated in the Romanian National Program. J. Transl. Med. Res 2015;20(2):55-66

21. Durand F, Renz JF, Alkofer B, Burra P, Clavien PA, Porte RJ, et al. Report of the Paris consensus meeting on expanded criteria donors in liver transplantation. Liver Transpl. 2008;14(12):1694-707.

22. Zota V, Popescu I, Ciurea S, Copaciu E, Predescu O, Costandache F, et al. Successful use of the liver of a methanol-poisoned, brain-dead organ donor. Transpl Int. 2003;16(6):444-6.

23. op den Dries S, Karimian N, Sutton ME, Westerkamp AC, Nijsten MW, Gouw AS, et al. Ex vivo normothermic machine perfusion and viability testing of discarded human donor livers. Am J Transplant. 2013;13(5):1327-35

24. Tolboom H, Izamis ML, Sharma N, Milwid JM, Uygun B, Berthiaume F, et al. Subnormothermic machine perfusion at both $20^{\circ} \mathrm{C}$ and $30^{\circ} \mathrm{C}$ recovers ischemic rat livers for successful transplantation. J Surg Res. 2012;175(1):149-56.

25. Schlegel A, Dutkowski P. Role of hypothermic machine perfusion in liver transplantation. Transpl Int. 2015;28(6):677-89. Epub 2014 Jun 30

26. Dutkowski P, de Rougemont 0, Clavien PA. Machine perfusion for 'marginal' liver grafts. Am JTransplant. 2008;8(5):917-24.

27. Popescu I. Living donor liver transplantation for hepatocellular carcinoma: defining criteria to extend indications. Dig Dis Sci. 2009; 54(2):199-200.

28. lacob S, Cicinnati VR, Hilgard P, lacob RA, Gheorghe LS, Popescu I, et al. Predictors of graft and patient survival in hepatitis $C$ virus (HCV) recipients: model to predict HCV cirrhosis after liver transplantation. Transplantation. 2007;84(1):56-63.

29. Gheorghe L, lacob S, Popescu I. Living donor liver transplantation and hepatitis C. Rom J Gastroenterol. 2004;13(4):317-27.

30. Tomescu DR, Dima S0, Ungureanu D, Popescu M, Tulbure D, Popescu I. First report of cytokine removal using CytoSorb ${ }^{\circledast}$ in severe noninfectious inflammatory syndrome after liver transplantation. Int J Artif Organs. 2016;39(3):136-40.

31. StarzI TE. The long reach of liver transplantation. Nature medicine. 2012;18(10):XIX-XII. 
32. GODT, Global Observatory on Donation and Transplantation International report on organ donation and transplantation activities. Executive summary 2018; october 2020. www.transplant-observatory.org.

33. European Committee (partial agreement) on organ transplantation, de scos. International figures on organ, tissue \& hematopoietic stem cell donation \& transplantation activities. Year 2013. Editor Rafael Matesanz. Newsletter Transplant, 2014;19(1):1-96.

34. lacob S, Gheorghe L, lacob R, Gheorghe C, Hrehoret D, Popescu I. MELD exceptions and new predictive score of death on long waiting lists for liver transplantation. Chirurgia (Bucur). 2009; 104(3):267-73

35. Gheorghe L, lacob S, lacob R, Smira G, Pietrareanu C, Hrehoret D, et al. Dynamics of the Romanian waiting list for liver transplantation after changing organ allocation policy. J Gastrointestin Liver Dis 2013;22(3):299-303.

36. Kim W R, Lake J R, Smith J M, Schladt D P, Skeans M A, et al. OPTN/SRTR 2016 Annual Data Report: Liver. Am J Transplant 2018; 18 (Suppl 1):172-253.

37. Patel YA, Berg CL, Moylan CA. Nonalcoholic Fatty Liver Disease: Key Considerations Before and After Liver Transplantation. Dig Dis Sci. 2016;61(5):1406-1416.

38. Estes C, Razavi H, Loomba R, Younossi Z, Sanyal AJ. Modeling the epidemic of nonalcoholic fatty liver disease demonstrates an exponential increase in burden of disease. Hepatology. 2018;67(1): 123-133.

39. Keswani RN, Ahmed A, Keeffe EB. Older age and liver transplantation: a review. Liver Transpl. 2004;10(8):957-67.

40. Smith B, de scos. Segmental liver transplantation from a living donor. J Pediatr Surg. 1969;4(1):126-32.

41. Organ Procurement and Transplantation Network, de scos. Nationa Data Reports 2014. http://optn.transplant.hrsa.gov/converge/ latestData/step2.asp.

42. de Villa V, Lo CM. Liver transplantation for hepatocellular carcinoma in Asia. Oncologist. 2007;12(11):1321-31.

43. Chan SC, Liu CL, Lo CM, Lam BK, Lee EW, Fan ST. Donor quality of life before and after adult-to-adult right liver live donor liver transplantation. Liver Transpl 2006;12:1529-1536.

44. Salah T, Sultan AM, Fathy OM, Elshobary MM, Elghawalby NA, Sultan A, et al. Outcome of right hepatectomy for living liver donors: a single Egyptian center experience. J Gastrointest Surg 2012;16 1181-1188.

45. Middleton P, Duffield M, Lynch S, Padbury RT, House T, Stanton P, et al. Living donor liver transplantation-Adult donor outcomes: A systematic review. Liver Transplantation 2005;12(1):24-30.

46. Nadalin S, Capobianco I, Panaro F, Di Francesco F, Troisi R, SainzBarriga M, et al. Living donor liver transplantation in Europe. Hepatobiliary Surg Nutr. 2016;5(2):159-75

47. Wan P, Zhang JJ, Li QG, Xu N, Zhang M, Chen XS, Han LZ, Xia Q. Living-donor or deceased-donor liver transplantation for hepatic carcinoma: a case-matched comparison. World J Gastroenterol. 2014;20(15):4393-400

48. Lee S, Hwang S, Park K, Lee Y, Choi D, Ahn C, et al. An adult-to-adult living donor liver transplant using dual left lobe grafts. Surgery 2001;129:647-50

49. Na BG, Park GC, Hwang S, Kim KH, Ahn CS, Moon DB, et al. Biliary complications after single- and dual-graft living-donor liver transplantation using a right posterior section graft of donor with a type III portal vein variation. Transplant Proc. 2020;52(6): 1838-1843.

50. deLemos AS, Vagefi PA. Expanding the Donor Pool in Liver Transplantation: Extended Criteria Donors. Clinical Liver Disease, 2013;2(4):156-159.

51. Vagefi PA, Parekh J, Ascher NL, Roberts JP, Freise CE. Outcomes with split liver transplantation in 106 recipients: the University of California, San Francisco, experience from 1993 to 2010. Arch Surg 2011:146:1052-1059.

52. Popescu I, Habib N, Dima S, Hancu N, Gheorghe L, lacob S, et al. Domino liver transplantation using a graft from a donor with familial hypercholesterolemia: seven-yr follow-up. Clin Transplant. 2009;23(4):565-70.

53. Popescu I, Dima SO. Domino liver transplantation: how far can we push the paradigm? Liver Transpl. 2012:18(1):22-8.

54. Liu C, Niu DM, Loong CC, Hsia CY, Tsou MY, Tsai HL, Wei C. Domino liver graft from a patient with homozygous familial hypercholesterolemia Pediatr Transplant. 2010;14(3):E30-3.

55. Belghiti J, Sommacale D, Dondéro F, Zinzindohoué F, Sauvanet A, Durand F. Auxiliary liver transplantation for acute liver failure. HPB (Oxford). 2004;6(2):83-87.

56. Adam R, Karam V, Delvart V, O'Grady J, Mirza D, Klempnauer J, et al. Evolution of indications and results of liver transplantation in Europe. A report from the European Liver Transplant Registry (ELTR). J Hepatol. 2012;57:675-688.

57. Matesanz R, de la Rosa G. Liver transplantation: The Spanish experience. Digestive and Liver Disease Supplements 2009;3: 75-81.

58. Busuttil RW, Tanaka K. The utility of marginal donors in liver transplantation. Liver Transpl. 2003;9(7):651-63.

59. Jiménez-Castro MB, Elias-Miró M, Peralta C. Expanding the Donor Pool in Liver Transplantation: Influence of Ischemia-Reperfusion. In: Organ Donation and Organ Donors. Nova Science Publishers, Inc. ISBN: 978-1-62618-853-2, 2013

60. Selzner N, Rudiger H, Graf R, Clavien PA. Protective strategies against ischemic injury of the liver. Gastroenterology 2003; 125(3):917-936.

61. Guarrera JV, Henry SD, Samstein B, Odeh-Ramadan R, Kinkhabwala $\mathrm{M}$, Goldstein MJ, et al. Hypothermic machine preservation in human liver transplantation: the first clinical series. Am J Transplant. 2010; 10(2):372-81.

62. Guarrera JV, Henry SD, Samstein B, Reznik E, Musat C, Lukose TI, et al. Hypothermic machine preservation facilitates successful transplantation of "orphan" extended criteria donor livers. Am J Transplant. 2015;15(1):161-9.

63. Dahlgren US, Bennet W. ABO-Incompatible Liver Transplantation - A Review of the Historical Background and Results. Int Rev Immunol. 2019;38(3):118-128. 